Boise State University

ScholarWorks

Counselor Education Faculty Publications and

Presentations

Department of Counselor Education

$7-1-2018$

Experiences of Middle School Counselors Learning and Applying Principles of Neuroscience

Raissa Miller

Boise State University

Laura Gallo

Boise State University

Lauren Moore

Boise State University 


\title{
Experiences of Middle School Counselors Learning and Applying Principles of Neuroscience
}

\author{
Raissa Miller \\ Boise State University
}

\author{
Laura Gallo \\ Boise State University
}

\author{
Lauren Moore \\ Boise State University
}

\begin{abstract}
Adolescence is a critical period of development during which time individuals' brains experience increased neuroplasticity and structural reorganization (Albert, Chein, \& Steinberg, 2013; Bava \& Tapert, 2010; Casey, Getz, \& Galvan, 2008). Neuroplasticity is the brain's ability to change in response to new learning and environmental influences (Siegel, 2012). A number of factors influence an individual's brain development and associated changes in affect, cognition, and behavior, including genetic predispositions, early childhood experiences, and temperament (Steinberg, 2014). For example, adolescents who have a history of Adverse Childhood Experiences (ACEs), a set of toxic experiences such as abuse or having a caretaker who is dependent on substances, often have unique patterns in brain development and are at an increased risk for engaging in anti-social behavior and/or experiencing psychological distress (Andersen et al., 2008; Duke, Pettingell, McMorris, \& Borowsky, 2010). Keeping in mind the complexity and uniqueness of individual experience, we will briefly review some of the most influential changes in adolescents' brains below.
\end{abstract}

One of the key developmental changes that occurs during adolescence is the process of pruning and myelination (Somerville, Jones, \& Casey, 2010). Pruning is the dying away of unused neurons and neural connections and myelination is the insulation of nerve fibers resulting in increased speed of communication (Somerville et al., 2010). These changes help the brain become more specialized and efficient. Casey et al. (2008) noted that the developmental progression of these processes is associated with many of the changes in affect, cognition, and behavior adolescents' experience. Notably, structures in the limbic region, a part of the brain most responsible for generating emotions, forming attachments, assessing risk and reward, and generating motivation, myelinate first. Structures in the prefrontal cortical areas, more dominant in logical decision-making, long-term planning, attention and focus, and impulse control myelinate second. This developmental sequence means that movement toward activities and people adolescents perceive as potentially rewarding occurs at a much quicker rate than the capacity to pause and reflect on values or consider long-term consequences (Galvan, 2010; Holder \& Blaustein, 2014).

In addition to structural changes, neurochemicals often fluctuate greatly during adolescence, resulting in increased sensitivity to rewards and stress (Somerville et al., 2010). For example, dopamine, a neurohormone that plays a critical role in affective and motivational regulation, increases when engaging in pleasurable activities resulting in such activities feeling even more enjoyable (Galvan, 2010; Steinberg, 2014). Additionally, the hypothalamic-pituitarygonadal (HPA) axis, which plays an important role in regulating stress, is more reactive, evidenced in part by increased levels of the hormone cortisol (Gunnar, Wewerka, Frenn, Long, \& Griggs, 2009). Adolescents are more likely to interpret neutral stimuli as threatening and react in a defensive or even hostile manner. Further, adolescents' secrete melatonin, a hormone associated with the feeling of sleepiness, later than children or adults resulting in a biological preference for later bedtimes (Crowley, Acebo, \& Carskadon, 2007). Insufficient sleep due to early school start times or poor nighttime sleep hygiene behaviors can exacerbate typical adolescent experiences, such as struggles with emotional regulation, information processing, and behavioral inhibition.

The structural and neurochemical changes that occur during adolescence can provide opportunities for greater creativity, openness, and learning (Casey et al., 2008). However, these changes can also result in negative experiences and outcomes (Bava \& Tapert, 2010). For example, many symptoms of psychological distress (e.g., anxiety, depression, distorted eating) have their onset during adolescence (Giedd, Keshavan, \& Paus, 2008). Environmental 
This is an author-produced, peer-reviewed version of this article. The final, definitive version of this document can be found online at Journal of Child and Adolescent Counseling, published by Taylor \& Francis. Copyright restrictions may apply. doi: 10.1080/23727810.2017.1381909

and relational supports can play a key role in minimizing these risks and maximizing potential positive growth (Jensen \& Nutt, 2015; Roaten \& Roaten, 2012; Whittle et al., 2014). School counselors serve as essential supports within an environment that adolescents spend a significant amount of time, school.

School counselors support adolescents through a number of activities, including individual and group counseling, classroom guidance lessons and large-scale programming, communication and information-dissemination to parents, consultation with teachers regarding how to support adolescents' success in the classroom, and advocacy to administrators for policies that create a healthy school climate (American School Counselor Association, 2009). Counselors who understand adolescent brain development and neuroscience informed practices are likely better equipped to effectively engage in these many important and influential tasks (Wigfield, Lutz, \& Wagner, 2005). Roaten and Roaten (2012) noted that "school counselors, through their comprehensive programs and making this knowledge available to teachers, administrators, parents, and students will undoubtedly improve the quality of counseling, educational services, and parenting” (p. 22). Many school counselors, however, are not aware of the latest findings in neuroscience and how those findings can inform their interactions with adolescents, parents, teachers, and administrators (D’Andrea, 2012; Roaten, 2011).

Empirical research on the value of counselors learning principles of neuroscience is limited; we were only able to identify one such study. In this study, Miller and Barrio Minton (2016) found a number of positive outcomes related to mental health counselors' experiences learning principles of interpersonal neurobiology. Themes included deepened knowledge and understanding of self and others, increased compassion, empathy, and acceptance of self and others, and modified clinical practice (e.g., case conceptualizations, selection of interventions, and psychoeducation). Although these findings suggest value in teaching neuroscience principles to counselors, a significant need exists to further explore the experiences of school counselors learning and applying principles of neuroscience. Such inquiry could further understanding related to the potential usefulness of neuroscience instruction in school counselors' education and professional development.

The purpose of this study was to explore middle school counselors' experiences learning and applying principles of neuroscience via a four-hour professional development training. We selected the four-hour continuing education training format because the length is consistent with other trainings school counselors commonly receive. We believed it was important to present the information in a practical and replicable manner.

We selected middle school counselors because their students are typically between the ages of 12 and 15, a time when individuals' brains undergo some of the most significant and critical neural changes and often need extra understanding and support from the adults in their lives (Holder \& Blaustein, 2014). As noted above, school counselors are in a unique position to support adolescents' development through direct interactions and consultation with key stakeholders in adolescents' lives (ASCA, 2009). Educating school counselors on principles of neuroscience could influence the interventions they choose for direct services and the information they share with parents, teachers, and administrators, thus directly supporting adolescents' healthy brain development during the critical early adolescent years.

The following questions guided our initial inquiry:

(1) What are the experiences of middle school counselors learning principles of neuroscience and adolescent brain development?

(2) How do these experiences impact middle school counselors' work with students, teachers, administrators, and parents?

(3) What, if any, barriers do middle school counselors perceive in applying principles of adolescent brain development to their work?

\section{Method}

The first author conducted the training. She has advanced training in neuroscience principles and has a considerable publication and presentation record related to the topic. The four-hour training included information on basic brain anatomy and neurochemicals, mechanisms of brain-based change (e.g., synaptogenesis, epigenesis, neurogenesis, and myelinogensis), and implicit and explicit memory. The training addressed adolescent-specific processes of pruning and myelination and the progression of brain development through the adolescent maturation process (e.g., 
This is an author-produced, peer-reviewed version of this article. The final, definitive version of this document can be found online at Journal of Child and Adolescent Counseling, published by Taylor \& Francis. Copyright restrictions may apply. doi: 10.1080/23727810.2017.1381909

myelination of the limbic system, prefrontal cortex, and then the linkages between the two regions). The training also covered unique aspects of adolescent brain development, such as adolescents' sensitivities to rewards and to stress, the impact of ACEs on functioning, and the influence of peers on cognitive executive functioning.

The final component of the training included reflection on possible applications of neuroscience within the school setting, including potential activities for supporting healthy brain development. One well-received activity was the Healthy Mind Platter (Rock, Siegel, \& Poelmans, 2012), a framework that illustrates and describes essential components related to supporting positive brain growth and functioning. Another popular activity was the Hand Model of the Brain (Siegel, 2012), a visual model of key brain regions using the palm of your hand as an analogy. Using the hand model, the trainer introduced the "flipping your lid" concept that describes how under significant stress, the parts of the brain responsible for impulse control, empathy, and creative problem solving become inhibited and the more reactive and emotional parts of the brain take the lead. The trainer also provided the school counselors with a number of resources (e.g., video titles, website links, and handouts) for future reference or use in their work.

We used an Interpretative Pheomenological Analysis (IPA) approach in designing and implementing this study. The IPA framework is ideal for exploring individuals' efforts to make sense of specific experiences (Smith, Flowers, \& Larkin, 2009). The approach is grounded in principles of phenomenology, hermeneutics, and idiography (Pietkiewicz \& Smith, 2014). Researchers utlizing IPA, focus on indviduals' first-person perspectives, reflect on their own interpretations of participants' meaning making, and examine individual cases in depth before broadening to shared or conflicting constructs. Pietkiewicz and Smith (2014) noted that "IPA synthesizes ideas from phenomenology and hermeneutics resulting in a method which is descriptive because it is concerned with how things appear . . . and interpretative because it recognizes there is no such thing as an uninterpred phenomenon” (p. 8). The framework provides flexible, yet systemic, guidance for data collection and analysis that supports the development of credible and trustworthy studies (Finlay, 2011).

\section{$\underline{\text { Participants }}$}

The population of interest for this study was middle school counselors who completed a four-hour training on principles of neuroscience and adolescent brain development. Consistent with IPA, we used purposive sampling to select a small sample ( $\mathrm{N=7}$ ) of relatively homogenous participants (Polkinghorne, 2005; Smith et al., 2009). Participants included three males and four females between the ages of 29 and 52 (mean age $=41$ years). All participants self-identified as white/caucasian. The participants worked at four different middle schools in a large school district in the Pacific Northwest. Participants all had a master's degree in counseling or a closely related field (e.g., Education Specialist in School Psychology) with years of expereince as a middle school counselor ranging from 1.5-11 (mean years of experience= 6). Characteristics of the individuals included in the study were generally representative of middle school counselors in the region. Pseudonyms are used to protect participants' privacy.

\section{Data Collection}

In line with IPA methodlogy, we conducted semi-structured individual interviews to gain rich explanations of participants' experiences (Englander, 2012; Polkinghorne, 2005; Smith et al., 2009). Two graduate research assistants trained in qualitative research and interviewing methods conducted the interviews in an effort to increase participants' comfort with sharing freely about what they learned in the training. The research assistants conducted pilot interviews and the first author listened to and provided constructive feedback on their qualitative interviewing skills before they engaged in the actual research interviews.

The first author developed the interview schedule based on recommendations by Smith et al. (2009) and Knox and Burkard (2013). The interview schedule included six open-ended-questions with optional follow-up prompts. The questions focused on the participants' experiences learning principles of neuroscience and adolescent brain development, as well as participants' experiences applying their learning with students, teachers, parents, and/or administrators. Additional questions included potential barriers to applying neuroscience-informed interventions in the schools and any future neuroscience-related training participants wished to have moving forward.

After IRB approval, the research assistants e-mailed all of the individuals who attended the four-hour training to inquire about interest in participating in the research study. These e-mails were sent out one-month post training in order to give participants time to experiment with applying their learning. The time frame was also useful in revealing 
This is an author-produced, peer-reviewed version of this article. The final, definitive version of this document can be found online at Journal of Child and Adolescent Counseling, published by Taylor \& Francis. Copyright restrictions may apply. doi: 10.1080/23727810.2017.1381909

what concepts or ideas stood out after a month or more post-training. The e-mail contained information about the study, as well as a basic research informed consent. Interested participants scheduled an interview with one of the two research assistants. Interviews took place in the participants' school counseling offices, consistent with Pietkiewicz \& Smith's (2014) recommendation for conducting interviews in a naturalistic setting. Before starting the interviews, participants completed a short demographic questionnaire and read and signed the formal informed consent document. The interviews were audio-recorded and transcribed. Each interview lasted between 40-60 minutes.

\section{Researcher Lens}

Researchers' prior knowledge and experiences play a role in understanding and interpreting participants' experiences (Smith et al., 2009). The first author had advanced training in neuroscience principles related to counseling, as well as experience publishing and presenting on the relevance of neuroscience to counseling. Neuroscience principles greatly influenced her orientation to counseling and her conceptulizations of the role of school counselors. The second author was an experienced school counselor who did not have signficant exposure to neuroscience before this project and thus served as a balance to potential biases of the first author throughout the research process. The third author was one of the two school counseling graduate students that conducted the interviews and transcribed the data. She did not have training or particular professional interest in neuroscience.

Research bias reflected findings from the limited literature on neuroscience and school counseling, namely that neuroscience was relevant to the work of school counselors and that learning neuroscience could help school counselors better understand students' experiences and ways to support their healthy development and functioning (Roaten \& Roaten, 2012). We acknowledged these biases prior to and throughout the analysis process so as not to miss the participants' actual perceptions and experiences (Finlay, 2011). Before beginning the interviews, the research assistants shared their values and beliefs related to the topic. A review of the pilot and actual interviews confirmed the interviewers' ability to avoid leading questions and encourage open and honest exploration of the research topic. Further, we maintained field notes throughout the analysis process and remained intentional, through journaling and discussion, about bracketing personal expectations related to the data (Yardley, 2008).

\section{Data Analysis}

We followed IPA's recommended six-step analysis process for data analysis (Smith et al., 2009). Working independently, we began with multiple readings of the transcripts in an effort to immerse ourselves in the data. We then recorded exploratory comments, focusing on participants' explicit meaning, as conveyed through content and linguistic expression, and initial interpretative reflections (Pietkiewicz \& Smith, 2014). After completing this detailed and comprehensive notetaking phase of the analysis, we moved on to identifying and recording emergent themes for individual cases. Smith et al (2009) noted that emergent themes "are usually expressed as phrases which speak to the psychological essence of the piece and contain enough particularity to be grounded and enough abstraction to be conceptual ... they reflect a synergistic process of description and interpretation” (p. 92). The idiographic focus in IPA required that we treated each case as its own analysis unit, intentionally bracketing themes from other cases when reading and reflecting on the current case. Only after we recorded emergent themes for all seven cases did we move into looking for patterns across cases to identify a set of master themes.

The first author reviewed both sets of emergent and master themes for each case and created a list of superordinate and subordinate themes that reflected patterns across cases. The second author reviewed the list and provided feedback regarding wording and supporting data. As a result of this consensus-seeking process, some superordinate and subordinate themes were combined, whereas others were deleted or added. The first author e-mailed a list of the final superordinate and subordinate themes, along with supporting quotes from the raw data, to all seven research participants in an effort to engage in the qualitative process of member checking. All seven members reviewed the list of themes and responded back affirming that the themes accurately represented their perceptions and experiences.

\section{Results}

Four superordinate themes emerged from the data analysis: neuroscience as relevant and useful, neuroscience as a helpful explanation for adolescent behavior, collaborating with key stakeholders, and barriers to application. The superordinate themes capture participants' shared perceptions and experiences about learning and applying principles 
This is an author-produced, peer-reviewed version of this article. The final, definitive version of this document can be found online at Journal of Child and Adolescent Counseling, published by Taylor \& Francis. Copyright restrictions may apply. doi: 10.1080/23727810.2017.1381909

of neuroscience in their work as school counselors. We also identified subordinate themes that reflect a more nuanced description of ideas connected to the larger superordinate themes. A complete list of superordinate and subordinate themes is provided in Table 1.

\section{Superordinate Theme 1: Neuroscience as Relevant and Useful}

\section{Subordinate Theme 1a: Ideas Resonate and Have Meaning}

All seven participants expressed a sense that they could either personally or professionally connect to the principles of neuroscience presented in the training. They were overwhelmingly positive in their assessments of the relevance of neuroscience for school counselors. In talking about the information shared in the training, Andy noted "it seemed really sensible and appropriate ... seemed like right on target and it made sense." Similarly, Teresa shared "I think learning about the anatomy of the brain was really interesting and the way it develops, I just thought it was all really applicable stuff to what I do every day.”

The participants shared examples of concepts that particularly stood out as applicable. These examples included the metaphor of the hand model of the brain, the concept of flipping your lid, and the practice of mindfulness (Rock, et al., 2012; Siegel, 2012). The participants did not seem bothered by the technical language presented, focusing more on the relevance of the information and on the implications. For example, Morgan noted "having it broken down into the hippocampus and the frontal lobes ... just all the pieces, even if I don't remember all of the names off the top of my head, it was helpful.” Pat echoed this sentiment, noting that "even though I don't know the specific scientific names of all of it, it made sense."

\section{Subordinate Theme 1b: Validating; Affirming and Building on Prior Knowledge}

In addition to connecting with the principles discussed in the training, the participants reported feeling a sense of validation that much of what they believe or are already doing as school counselors is consistent with brain science. Although familiarity with neuroscience concepts varied among participants, the majority communicated a sense that the training added to and/or deepened their prior knowledge base. Jean shared "for me it kind of reaffirms things, I am a very Adlerian based counselor ... . a lot of the parenting strategies and things that I adhere to are very much about understanding, especially in conflict, what happens in the brain." Bobbie expressed a sense of relief, noting "it was confirming some of the things that I am sharing, so that was good, because I do not want to be sharing misinformation."

In addition to validation, some participants perceived neuroscience as lending credibility to certain types of interventions. Morgan shared "I feel like I have a better buy-in . . . its not just somebody making stuff up and hoping it works, it is like "here is the part of the brain that needs development right now ... we can understand and now we start working on that." Teresa reflected on the training and noted the supportive and integrative manner neuroscience information can have, stating "it solidified that and confirmed and kind of brought together everything that I kind of know.

\section{Subordinate Theme 1c: Focus on Practical, Concrete Resources}

Although participants spoke positively about many aspects of the training, there seemed to be a particular appreciation for the specific resources and activity ideas. The most frequently cited resources were the healthy mind platter (Rock et al., 2012) and the hand model of the brain (Siegel, 2012). Jean said "the brain platter that she shared with us, I never had seen anything like that before and immediately that was something that both my co-counselor and I thought we could use." Andy similarly noted that the healthy mind platter "seemed like the summary of everything we had worked on, something nice and tangible that we could put to use for kids." Referencing the hand model of the brain, Teresa said "that is why I remember the brain thing, because it is a visual, and being able to do it, those are probably the most helpful things."

Participants also spoke about the importance of having resources to share with others, particularly resources that were not too lengthy or time consuming to explain. Speaking about what stood out from the training, Kerry said "I think the resources provided, the links, I mean here are some great online guides . . . great online web sources.” Teresa noted her appreciation for "things I can give teachers ... or little bookmarks ... just different things that I can share 
This is an author-produced, peer-reviewed version of this article. The final, definitive version of this document can be found online at Journal of Child and Adolescent Counseling, published by Taylor \& Francis. Copyright restrictions may apply. doi: 10.1080/23727810.2017.1381909

quickly." Morgan said "I think that nice, one sheet of paper sort of thing, we can reference really easy, probably make that easier to implement." The need for a curriculum also came up in many of the interviews. Jean noted "if there was a curriculum . . . based off this information that could be shared, that would be super helpful.”

\section{Subordinate Theme 1d: Importance of Ongoing Learning}

The need and desire for multiple exposures to the information covered in the training came up in the majority of participants' interviews. For some participants, this training seemed to serve as a reminder of prior learning, whereas for others, the training was their first introduction to principles of neuroscience relevant to school counseling. Participants seemed to believe that repeated trainings were essential for getting the information translated into actual practice. Andy said it was "really nice to re-pattern and again thicken that knowledge and build it more into behavior, rather than just knowledge." Kerry stressed that if school counselors "only heard this once and they are not even aware this is a tool they can use, it is pretty hard to implement it in the schools . . . the effects, unfortunately, of one time trainings wears off after about a week, a month at most." Teresa reflected "you just need refresher courses cause your brain keeps adding more and more stuff and it just gets packed down, so bringing it back to the forefront." Similarly, Morgan noted that "sometimes I think they have a good understanding but it gets lost along the way when you have so many other things to think about ... just having that reminder."

\section{Subordinate Theme 1e: Integration into Current Work}

The relevance and usefulness of learning about neuroscience principles was apparent in participants' sharing of recent examples in which they, in some manner, integrated learning from the training into their work. For example, Kerry noted "I actually just had a conversation with a student a couple days ago about the healthy mind platter." In talking about his interaction with a specific student, Andy noted that the information from the training helped him "think about how he is thinking and design some kind of intervention that will get him to make some different choices and connect with different rewards, see that those are there and see some value in them." Teresa said "I have got a parent group right now ... talking about choice making and the influence of peers, how that takes over, kind of trumps the parent and how being around peers pushes them to do things that they might not do with family." In talking about work with a parent, Morgan noted "I said let's get on the internet real quick and lets look up this brain development piece.”

Participants also shared about how they envisioned integrating neuroscience-informed interventions or information into their work in the future. The most frequently cited examples included parent education, small counseling groups, and guidance lessons. There seemed to be an emphasis on integration with, rather than replacement of their current programs. For example, Pat spoke about the importance of "finding a way to tie it in to what we already have going, so it is not like something new or different, but just an enhancement to what we are already doing." Morgan shared her plan for integration: "incorporating the brain science even if it is just a little . . going to start for two minutes, three minutes, five minutes, just doing this as part of our group."

\section{Superordinate Theme 2: Neuroscience as a Helpful Explanation for Adolescent Behavior}

\section{Subordinate Theme 2a: Normalizing}

Participants repeatedly used neuroscience to normalize common adolescent experiences. The most frequently mentioned experiences were increased risk taking, changes in adolescents' sleep cycle, the influence of peers on decision making, and the impact of developmental traumas on development and functioning. Bobbie suggested "a lot of the things that you see developmentally with kids is based in brain development . . f for example ... executive functioning issues that kids have at this age." Teresa shared "their emotions are heightened and they are much more sensitive to things, they don't necessarily make choice that are rational at the moment because of emotions.” Kerry noted "I think brain development plays a key role in explaining behavior ... kids will do silly things and they are not always in a position to have the tools to make a rational choice." 
This is an author-produced, peer-reviewed version of this article. The final, definitive version of this document can be found online at Journal of Child and Adolescent Counseling, published by Taylor \& Francis. Copyright restrictions may apply. doi: 10.1080/23727810.2017.1381909

\section{Subordinate Theme 2b: Shifting Negative Attitudes}

Participants spoke repeatedly of using neuroscience to improve individuals' perception of adolescents. Many participants noted that key stakeholders often become frustrated with students' behaviors and lose perspective, responding punitively rather than empathically. For example, Morgan stated "to empathize or understand where these kids are coming from a little bit more or where their brains might be because sometimes it is easy to look at them like little adults and wonder why they are doing some things so off kilter.” Kerry noted

I think teachers can take things personally, we all can, so if we can somehow soften the blow with 'there is a process here, you can't take it personal', I think sometimes that helps and it kind of gives them maybe an understanding of how to approach challenging kids.

They shared that sometimes individuals see the risks and problems associated with this unique developmental period and fail to notice and capitalize on the many opportunities. Talking specifically about adolescents' sleep cycles, Bobbie stated "I don't see it as a moral failing on the parents or on the child's point of view, I really see it as this person's sleep cycle is just off." Pat stated "I like the reframing . . . what risk taking means, what the social connectedness piece means ... more thoughtful perspectives."

\section{Subordinate Theme 2c: Increasing Students' Self-Understanding}

A third subtheme related to neuroscience as an explanation related to how participants' used or envisioned using this information to help increase students understanding of themselves. Participants conveyed a sense that many adolescents struggled with understanding their own inclinations and struggles and often viewed themselves as faulty. Teresa said

sometimes they don't even understand why they are checked out or uninterested in what is going on around them except for what their friends are doing ... humans like to know what is going on is somewhat normalized behavior. . . they want to know that they are not alone.

Many participants mentioned outcomes related to developmental trauma and how important it was for students to understand the effects. For example Kerry, in discussing ACEs scores (Duke et al., 2010), said that he talks with students about "how that [ACEs scores] makes them different than the person to the left and right of them."

Participants also shared about how they sought to engage students in reflecting on their own brain development and through that awareness, make healthier and more pro-social choices. Andy shared "being able to take it and bring it to the kids and get them to integrate it and get a little better self-reflection and be able to understand kind of where they are going and why sometimes they end up in the corners they do." Teresa said "I think kids need to know that friends can really influence me even if I think I have got my head on straight.”

\section{Superordinate Theme 3: Collaborating with Key Stakeholders}

\section{Subordinate Theme 3a: Collaborating with and Educating Teachers}

Participants talked frequently about their work with teachers. Sometimes this work was partnering with teachers so that they could integrate neuroscience into their classroom instruction. For example, Kerry noted that he collaborates with the health teacher at his school. He shared about recent lessons related to the impact of stress on the brain. Other participants talked more about their role in teaching teachers about principles of neuroscience. Jean noted that she can "see in the future some type of teacher in-service training that would be really beneficial." Similarly, Pat suggested that "counselors meet with teachers weekly and talk about issues that are presenting for students . . . I can see that being a great place to share knowledge."

\section{Subordinate Theme 3b: Teaching Parents About Adolescent Brain Development}

The majority of participants shared about educating parents. Some participants seemed to prefer giving adolescent brain development literature to parents, whereas others favored conversations. Pat talked about a mindfulness group she was running with students and noted that she could see providing parents of those students with some psychoeducational material on the brain, suggesting saying something like "here are some parenting resources that 
This is an author-produced, peer-reviewed version of this article. The final, definitive version of this document can be found online at Journal of Child and Adolescent Counseling, published by Taylor \& Francis. Copyright restrictions may apply. doi: 10.1080/23727810.2017.1381909

can help in the area of mindfulness.” Morgan recounted a recent conversation with a parent, sharing

I do remember working with a parent on executive function, I said 'let's start with where your student's or where your child's brain is developing right now ... here are some things that might help strengthen that piece' and again we popped on the internet and took a look at some of that stuff.

All of the participants noted that parents generally responded positively to neuroscience information. For example, Jean shared "going more in depth of what is happening in their brains at that point in time ... the response has been really positive ... they have been 'oh I never knew that, that is surprising, where can I read about that?'” Teresa noted "parents tend to forget, I think, being a teenager is somewhat a traumatic event for a lot of people . . being able to educate parents that a lot of these behaviors are normal really helps.”

\section{Subordinate Theme 3c: Integrating Neuroscience-Informed Information Across the School System}

Beyond educating teachers and parents, participants talked about ways they could use neuroscience research to advocate for larger systemic changes that support adolescents' healthy development. They expressed a need for widespread education and integration of brain development. Kerry suggested "partnering with the student services, probably at the district level, to try to integrate and update our curriculum." Some participants spoke more specifically about changes needed in the school system. For example, Bobbie said "the big way I am imagining it is we restructure the school day ... we start later ... I think that is a huge acknowledgment of adolescent brain development.” Bobbie also suggested longer class periods, noting "one of the things that seems primary is for students to have a relationship with their teachers ... so maybe that students go to less classes and spend more time going to the, you know, 45 minutes is not enough."

\section{Superordinate Theme 4: Barriers to Application}

\section{Subordinate Theme 4a: Limited Time}

The most frequently cited barrier to applying principles of neuroscience in participants' work with adolescents was time. Participants considered how much time it would take to teach others about neuroscience or implement new curriculum. They expressed concern about taking time away from other important tasks in order to learn or implement new practices and even acknowledged a bit of hesitation in trying something new. Kerry acknowledged "time is always a barrier." Similarly, Pat lamented "I just need some time.”

Participants spoke about their many obligations and roles as school counselors. They shared about being overextended at times, fulfilling expectations of a number of different individuals and entities. Teresa shared "I always think of us as the nucleus of the school because not only are we there trying to help support students and parents, but we have to make administrators happy, we have to make sure our staff is feeling supported." Kerry noted "there are 4700 things we are responsible for or try to do here.” Morgan noted

with time being so restrictive and it seems like most minutes of your day are spoken for and if they're not they quickly get spoken for by something that comes up . . . change then becomes really hard ... you don't have time to institute something new.

\section{Subordinate Theme 4b: Conflicting Priorities}

In speaking about other potential barriers to implementation, participants noted potential conflicts of interest between administrators and policy makers. Although these barriers did not come up as universally as the barrier of time, they seemed significant. Bobbie noted "why do we have kids going to school as early as we do when we know that the science tells us that it does not work for these guys ... .I feel frustrated that we don’t respect that.”

Many participants seemed to feel limited by administrator-defined instructional time. They conveyed a sense that they did not have enough opportunities to work with the majority of students on a regular basis. Teresa shared "we only get into the classroom one period a year to spend time with kids, I would love to do more." Kerry posed the dilemma "we want to be respectful of the teachers' time ... how can we be respectful of them and not take up too many classroom days?” 
This is an author-produced, peer-reviewed version of this article. The final, definitive version of this document can be found online at Journal of Child and Adolescent Counseling, published by Taylor \& Francis. Copyright restrictions may apply. doi: 10.1080/23727810.2017.1381909

\section{Subordinate Theme 4c: Insufficient Counselor Knowledge}

The final barrier participants frequently cited related to their own competence and or confidence to apply neuroscience principles. As noted previously, familiarity with neuroscience principles varied among participants and individuals with less exposure expressed more hesitancy in sharing the information with others. For example, Pat noted "I don't know enough to feel competent ... I don't know enough to share the knowledge of it yet.” Morgan acknowledged "there is a lot of information and it's going to be hard to remember all of it and implement things." Participants seemed open to additional learning in order to address this barrier. Pat stated "I would say it is a work in progress for me ... I am in the process of becoming or trying to be more educated about it."

\section{Discussion}

Findings suggest the potential usefulness of teaching principles of neuroscience to school counselors. This finding is consistent with existing literature on the perceived relevance of neuroscience principles in working with adolescents, especially within schools (Roaten \& Roaten, 2012; Wigfield et al., 2005), as well as literature on the value of counselors learning principles of neuroscience (Miller \& Barrio Minton, 2016). Of particular note, participants highlighted the value of using neuroscience to explain behavior as a means to decrease blame and shame. They referred to teachers and parents taking adolescents' behaviors personally, developing negative attitudes and nonconstructive ways of responding. Many of the participants also shared about adolescents' negative self-perceptions and struggles with self-acceptance. Although these struggles mirror common conceptions of the adolescent developmental period (Albert et al., 2013; Blakemore \& Mills, 2014), there appears to be some value in conceptualizing these struggles from a neuroscience lens. Increasing understanding and compassion, the opposites of blame and shame, is critical for fostering empathy and forming respectful and supportive relationships with adolescents (Holliman \& Foster, 2016; Smith-Adcock \& Pereira, 2017; Whittle et al., 2014). Any intervention that helps adolescents connect to peers and adults in a meaningful manner is worth consideration.

Although participants seemed to find great value in learning and applying neuroscience principles in their work, they also acknowledged real and troublesome barriers to applying their learning. The barrier of time in particular is not new to the field of school counseling. School counselors face a number of demands on their time, as they are expected to balance prevention and intervention with a number of individuals, each of whom have unique, and sometimes competing, needs (Dollarhide \& Saginak, 2017). Use of time has been a consistent issue in the field of school counseling and was one of the primary reasons the American School Counseling Association (ASCA; 2012) developed the 'Inappropriate versus Appropriate Duties' document, a resource counselors can use to plan and advocate for how they divide their time and responsibilities. Leaders in ASCA have also led the way in encouraging school counselors to collect data on their work so they can demonstrate effectiveness within a culture focused on accountability.

Finally, the participants also highlighted a need for additional training and exposure to the neuroscience material in order to translate their learning into actual changes in their work with adolescents and other key stakeholders. This finding is consistent with the larger literature on adult learning and counselor development (Cozolino \& Sprokay, 2006). Individuals are more likely to incorporate new knowledge into practice if they have ongoing support through additional trainings and/or consultation. The evolving nature of neuroscience research also warrants ongoing professional development, findings that are relevant today may not be relevant tomorrow.

\section{$\underline{\text { Limitations }}$}

We adhered to best practices for designing and implementing qualitative research studies in order to increase trustworthiness; however, our study does have limitations that should be taken into account when interpreting the findings. We only used one method of data collection: interviews. Some participants may have been more open to sharing their perspectives through writing or in a group setting (e.g., focus groups). We believe, however, based on the participants' background in counseling and experience with reflecting on learning, that they were able to adequately express their experiences and related thoughts, feelings, and behaviors. 
This is an author-produced, peer-reviewed version of this article. The final, definitive version of this document can be found online at Journal of Child and Adolescent Counseling, published by Taylor \& Francis. Copyright restrictions may apply. doi: 10.1080/23727810.2017.1381909

Another limitation includes the possibility that only the school counselors who found the training useful and relevant volunteered to be research participants. Although this occurrence is a real possibility, the idea that neuroscience is relevant to the work of school counselors is not limited to this study alone. We have found through informal discussions with individuals that most school counselors are enthusiastic and open to learning principles of neuroscience, although we have no systemic way of verifying this statement in the present study.

A final limitation includes the nature of IPA process. As is the case with all qualitative studies, the findings could vary with different research participants and/or researchers. Participants were relatively homogenous in ethnicity, training, and experience and are all localized to one region of the country. The subjective and interpretative perspectives they shared, however, were rich in detail and conveyed a sense of genuine meaning, and thus, sufficient for the present study design and focus.

\section{$\underline{\text { Implications }}$}

Our findings, in combination with existing literature on the usefulness of counselors learning and applying neuroscience, offer several implications for school counselors and individuals providing training to school counselors. School counselors seem to be genuinely interested in learning and applying principles of adolescent brain development. However, they also noted the need for more training opportunities and time to implement new ideas within their schools. Increasing opportunities for professional development related to topics of neuroscience and brain development could positively impact their work with adolescents, families, and other stakeholders. Partnerships between university faculty, who generally have greater access to the latest scientific advances and scholarship, and school counselors, who are on the front lines of applying interventions with adolescents and individuals within their systems of influence, may be a good starting point. School counselors and counselor educators could work together to provide professional development and information dissemination opportunities for adolescents, teachers, and administrators, as well as collaborate on research projects that assess new or existing interventions.

There also seems to be a need for the development of concrete resources and/or curriculum related to neuroscience principles that can be used with adolescents, teachers, parents, and administrators. Because of barriers in time and confidence, having quality materials for guidance lessons, individual or group counseling, parent education, teacher consultation, and advocacy efforts is likely to increase counselors' incorporation of neuroscience-informed practices into their work. Currently, a number of mindfulness-based curricula exist for implementation in schools and with families (Broderick \& Jennings, 2014; Meiklejohn et al., 2012). These programs generally cite neuroscience principles as their foundation and aim improve executive functioning and emotion regulation. The MindUP curriculum, however, is one of the only existing curricula we found that integrates teaching students specifically about the brain (Schonert-Reichl et al., 2015). MindUP is designed as a teacher-delivered program, but the social-emotional learning modules could be implemented by counselors. Each of the 15 lessons includes education about the brain, as well as brain-based experiential and reflective activities intended to foster greater attention, focus, regulation, resilience, and compassion.

Finally, the use of neuroscience within the field of school counseling is relatively new. For this reason, additional research is needed to better understand how teaching counselors and youth about brain development affects their learning and behaviors. Studies that allow for more varied participants and methodological approaches could provide valuable insight. Identifying student outcomes from counselors who have utilized neuroscience-informed practices or engaged in neuroeducation could also be helpful in understanding the impact of these concepts within the field.

In conclusion, school counselors in this study experienced learning principles of neuroscience and adolescent brain development as validating, relevant, and potentially useful to their work with adolescents and individuals within adolescents' systems of influence. The participants seemed to most appreciate how neuroscience can be used to normalize common struggles during the adolescent developmental period, allowing for increased understanding and relational support. Participants also acknowledged a number of barriers to applying neuroscience principles in their work with adolescents, teachers, parents, and administrators. These barriers provide an important direction for developing future counselor trainings, as well as for advocating for school counselors and policies within school systems that can better support adolescents' healthy development. 
This is an author-produced, peer-reviewed version of this article. The final, definitive version of this document can be found online at Journal of Child and Adolescent Counseling, published by Taylor \& Francis. Copyright restrictions may apply. doi: 10.1080/23727810.2017.1381909

\section{References}

Albert, D., Chein, J., \& Steinberg, L. (2013). The teenage brain: Peer influences on adolescent decision making. Current Directions in Psychological Science, $X X(X)$, 1-7. doi: 10.1177/0963721412471347

American School Counselor Association. (2009). The role of the school counselor. Retrieved from http://www.schoolcounselor.org/asca/media/asca/home/rolestatement.pdf.

American School Counselor Association. (2012). The ASCA national model: A framework for school counseling programs ( $\left.{ }^{\text {rd }} \mathrm{Ed}\right)$. Alexandria, VA: Author.

Andersen, S. L., Tomada, A., Vincow, E. S., Valente, E., Polcari, A., \& Teicher, M. H. (2008). Preliminary Evidence for Sensitive Periods in the Effect of Childhood Sexual Abuse on Regional Brain Development. The Journal of Neuropsychiatry and Clinical Neurosciences, 20, 292-301. doi: 10.1176/appi.neuropsych.20.3.292

Bava, S., \& Tapert, S. F. (2010). Adolescent brain development and the risk for alcohol and other drug problems. Neuropsychogical Review, 20, 398-413. doi: 10.1007/s11065-010-9146-6

Blakemore, S. J., \& Mills, K. L. (2014). Is adolescence a sensitive period for sociocultural processing? Annual Review Psychology, 65, 187-207. doi: 10.1146/annurev-psych-010213-115202

Broderick, P. C., \& Jennings, P. A. (2012). Mindfulness for adolescents: A promising approach to supporting emotion regulation and preventing risky behavior. New Directions for Youth Development, 116, 111-126. doi: 10.1002/yd.20042

Casey, B. J., Getz, S., \& Galvan, A. (2008). The adolescent brain. Developmental Review, 28, 62-77.

Crowley, S. J., Acebo, C., \& Carskadon, M. A. (2007). Sleep, circadian rhythms, and delayed phase in adolescence. Sleep Medicine, 8, 602-612. doi:10.1016/j.sleep.2006.12.002

Cozolino, L., \& Sprokay, S. (2006). Neuroscience and adult learning. New Directions in Adult and Continuing Education, 110, 11-19. doi:10.1002/ace.214

D’Andrea, M. (2012). Neuroscience: The newest force in counseling and psychotherapy. In A. Ivey, M. D’Andrea, M. Ivey (Eds.), Theories of counseling and psychotherapy: A multicultural perspective ( ${ }^{\text {th }}$ Ed) (pg. 49-86). Thousand Oak, CA: Sage.

Dollarhide, C. T. \& Saginak, K. A. (2017). Comprehensive school counseling programs: K-12 delivery systems in action ( $\left.3^{\text {rd }} \mathrm{Ed}\right)$. Boston, MA: Pearson.

Duke, N. N., Pettingell, S. L., McMorris, B. J., \& Borowsky, I. W. (2010). Adolescent violence perpetration: Associations with multiple types of adverse childhood experiences. Pediatrics, 125, e778-786.

Englander, M. (2012). The interview: Data collection in descriptive phenomenological humanscientific research. Journal of Phenomenological Psychology, 43, 13-35. doi: 10.1163/156916212X632943

Finlay, L. (2011). Phenomenology for therapists: Researching the lived world. West Suusex, United Kingdom: Wiley-Blackwell.

Galvan, A. (2010). Adolescent development of the reward system. Frontiers in Human Neuroscience, 4, 1-9. doi:10.3389/neuro.09.006.2010.

Giedd, J. N., Keshavan, M., \& Paus, T. (2008). Why do many psychiatric disorders emerge during adolescence? Nature Reviews Neuroscience, 9, 947-957. doi:10.1038/nrn2513.

Gunnar, M. R., Wewerka, S., Frenn, K., Long, J. D., \& Griggs, C. (2009). Developmental changes in hypothalamuspituitary-adrenal activity over the transition to adolescence: normative changes and associations with puberty. Development and Psychopathology, 21, 69-85. doi: 10.1017/S0954579409000054

Holder, M. K., \& Blaustein, J. D. (2014). Puberty and adolescence as a time of vulnerability to stressors that alter neurobehavioral processes. Frontiers in Neuroendocrinology, 35, 89-100. doi: 10.1016/j.yfrne.2013.10.004

Holliman, R. P., \& Foster, R. D. (2016). Embodying and communicating authenticity in adolescent counseling. Journal of Child and Adolescent Counseling, 2, 61-76. doi:10.1080/23727810.2016.1160353

Jensen, F. E. \& Nutt, A. E. (2015). The teenage brain: A neuroscientist's survival guide to raising adolescents and young adults. New York, NY: HarperCollins.

Knox, S., \& Burkard, A. W. (2013). Qualitative research interviews: An update. In W. Lutz \& S. Knox (Eds.), Quantitative and qualitative methods in psychotherapy research (pp. 342-354). Oxford, United Kingdom: Routledge.

Meiklejohn, J., Phillips, C., Freedman, L., Griffin, M. L., Biegel, G., Roach, A., . . Saltzman, A. (2012). Integrating mindfulness training into K-12 education: Fostering the resilience of teachers and students. Mindfulness, 3, 291-307. Doi: 10.1007/s12671-012-0094-5

Miller, R. M., \& Barrio Minton, C. A. (2016). Experiences learning interpersonal neurobiology: An interpretative phenomenological analysis. Journal of Mental Health Counseling, 38, 47-61. doi: 10.17744/mchc.38.1.04 
This is an author-produced, peer-reviewed version of this article. The final, definitive version of this document can be found online at Journal of Child and Adolescent Counseling, published by Taylor \& Francis. Copyright restrictions may apply. doi: 10.1080/23727810.2017.1381909

Pietkiewicz, I., \& Smith, J. A. (2014). A practical guide to using interpretative phenomenological analysis in qualitative research psychology. Psychological Journal, 20, 7-14. Doi:10.14691/CPPJ.20.1.7

Polkinghorne, D. E. (2005). Language and meaning: Data collection in qualitative research. Journal of Counseling Psychology, 52, 137-145. doi:10.1037/0022-1067.52.2.137

Roaten, G. K. (2011) Innovative and brain-friendly strategies for building a therapeutic alliance with adolescents. Journal of Creativity in Mental Health, 6(4), 298-314. doi:10.1080/15401383.2011.630306

Roaten, G. K., \& Roaten, D. J. (2012). Adolescent brain development: Current research and the impact on secondary school counseling programs. Journal of School Counseling, 10. Retrieved from http://www.jsc.montana.edu/articles/v10n18.pdf

Rock, D., Siegel, D. J., Poelmans, S. A. Y., \& Payne, J. (2012). The healthy mind platter. NeuroLeadership Journal, 4, 1-23.

Schonert-Reichl, K. A., Oberle, E., Lawlor, M. S., Abbott, D., Thomson, K., Oberlander, T. F., \& Diamond, A. (2015). Enhancing cognitive and social-emotional development through a simple-to-administer mindfulness-based school program for elementary school children: A randomized control trial. Developmental Psychology, 51, 52-66. doi: 10.1037/a0038454

Siegel, D. J. (2012). The developing mind: How relationships and the brain interact to shape who we are ( ${ }^{\text {nd }}$ Ed.). New York, NY: The Guilford Press.

Smith, J. A., Flowers, P., \& Larkin, M. (2009). Interpretative phenomenological analysis: Theory, method, and research. Thousand Oaks, CA: SAGE Publications, Inc.

Smith-Adcock, S., \& Periera, J. (2017). The counseling process: Establishing a therapeutic alliance. In S. SmithAdcock \& C. Tucker (Eds.), Counseling children and adolescents (pp. 98-122). Thousand Oaks, CA: SAGE Publications.

Somerville, L. H., Jones, R. M., \& Casey, B. J. (2010). A time of change: Behavioral and neural correlates of adolescent sensitivity to appetitive and aversive environmental cues. Brain Cognition, 72, 124-133. doi:10.1016/j.bandc.2009.07.003.

Steinberg, L. (2014). Age of opportunity: Lessons from the new science of adolescence. New York, NY: Houghton Mifflin Harcourt Publishing

Whittle, S., Simmons, J. G., Dennison, M., Vijayakumar, N., Schwartz, O., Yap, M. B. H., Sheeber, L., \& Allen, N. B. (2014). Positive parenting predicts the development of adolescent brain structure: A longitudinal study. Developmental Cognitive Neuroscience, 8, 7-17. doi: 10.1016/j.dcn.2013.10.006

Wigfield, A., Lutz, S. L., \& Wagner, A. L. (2005). Early adolescents development across the middle school years: Implications for school counselors. Professional School Counseling, 9(2).

Yardley, L. (2008). Demonstrating validity in qualitative psychology. In J. Smith (Ed.), Qualitative psychology: A practical guide to research methods (pp. 235-251). Thousand Oaks, CA: SAGE Publications.

\section{Table 1}

Superordinate and Subordinate Themes

\begin{tabular}{ll}
\hline Superordinate Theme & Subordinate Theme \\
\hline Neuroscience as relevant and useful & Ideas resonate and have meaning \\
& Validating; affirming and building on prior knowledge \\
& Focus on practical, concrete resources \\
& Importance of ongoing learning \\
& Integration into current work \\
Neuroscience as a helpful explanation for adolescent & Normalizing \\
behavior & Shifting negative attitudes \\
Collaboration with key stakeholders & Increasing students' self-understanding \\
& Collaborating with and educating teachers \\
& Teaching parents about adolescent brain development \\
& Integrating neuroscience-informed information across \\
the school system & Limited time \\
Barriers to application & Conflicting priorities \\
& Insufficient counselor knowledge \\
\end{tabular}

